\title{
Deep sternal wound infection after open heart surgery: current treatment insights. A retrospective study of 36 cases
}

\author{
Rutger M. Schols • Thomas M. A. S. Lauwers • \\ Gijs G. Geskes • René R. W. J. van der Hulst
}

Received: 15 December 2010 / Accepted: 16 March 2011/Published online: 12 April 2011

(C) The Author(s) 2011. This article is published with open access at Springerlink.com

\begin{abstract}
The aim of this study was to retrospectively evaluate the results of reconstructing infected poststernotomy wounds, with either sternal plating and/or pectoralis major flap transposition or pedicled omentoplasty after previous vacuum-assisted closure (VAC) therapy. Between January 2005 and December 2010, 36 patients, suffering from deep sternal wound infection (DSWI) after coronary artery bypass grafting procedure, received (plastic) reconstructive surgery. All patients, treated in the Maastricht University Medical Centre (Departments of Plastic Surgery and Cardiothoracic Surgery), were selected for this study. For 22 patients, sternal refixation and reconstruction were obtained by sternal internal plate fixation combined with bilateral pectoralis major advancement flap. In 11 patients, a pedicled omentoplasty was performed, with or without splitskin graft and additional VAC therapy. Three patients only received a pectoralis plasty. We evaluated preoperative characteristics and post-operative course. Twenty-four patients $(66.7 \%)$ had an uneventful post-operative course. Complications in the other patients included wound dehiscence, herniation of the donor site and infection of sternal plating material. Average sternal wound healing after sternal plating plus pectoralis plasty, pectoralis plasty and omentoplasty respectively accounted 7.7, 8.0 and 11.6 weeks. From our experience, we recommend
\end{abstract}

\footnotetext{
R. M. Schols $(\bowtie) \cdot$ T. M. A. S. Lauwers $\cdot$

R. R. W. J. van der Hulst

Department of Plastic, Reconstructive and Hand Surgery,

University Hospital Maastricht,

PO Box 5800, 6202 AZ Maastricht, The Netherlands

e-mail: rm.schols@student.maastrichtuniversity.nl

G. G. Geskes

Department of Cardiothoracic Surgery, University Hospital Maastricht,

PO Box 5800, 6202 AZ Maastricht, The Netherlands
}

VAC therapy plus delayed sternal plating and additional bilateral pectoralis major flap advancement as first repair option in case of DSWI. However, individual clinical conditions need to be taken into account when making a decision between the different available reconstructive options. Omentoplasty should be reserved for cases in which the sternum has recurrently fallen open after previous sternal plate refixation, or for cases in which the sternum defect is too extended.

Keywords Deep sternal wound infection - VAC therapy . Sternal plating $\cdot$ Pedicled omentoplasty $\cdot$ Pectoralis major flap advancement

\section{Introduction}

Plastic surgeons are often consulted to assist with reconstruction of chest wall defects, after tumour resection or for chronic or complicated deep sternal wound infection (DSWI) after open heart surgery. DSWI occurs in about $1-2 \%$ of patients, who have undergone median sternotomy for cardiac surgery. Therefore, it is a rare postoperative complication, but postoperative mortality (until 30 days after surgery) in patients with DSWI is significantly higher (7.3\%) than in patients without DSWI (1.6\%), although survival on the long-term does not seem to be compromised $[1,2]$.

Repair of sternal defects, compromised with infection, can be achieved in several ways [3]:

- primary wound closure in combination with irrigation [4];

- local negative pressure therapy, also known as vacuumassisted closure (VAC) therapy. VAC-therapy is more 
or less accepted as the first-line intervention for poststernotomy mediastinitis, as a consequence of excellent clinical results, which have been achieved by using this form of therapy [5, 6];

- VAC-therapy followed by definitive wound closure or sternal refixation using sternal plating [7];

- primary or delayed flap closure by the use of regional myocutaneous flaps (myoplasty), such as the pectoralis major flap, the rectus abdominus flap and the latissimus dorsi flap; or by the transposition of the greater omentum, with or without split-skin grafting [8].

There is no consensus on which of these options is superior. Several publications recommend omentoplasty for reconstruction of chest wall defects after tumour resection or post-sternotomy mediastinitis after CABG (coronary artery bypass grafting) or as a final solution when muscle flaps have failed $[3,8]$. The main goal of this study is to evaluate the outcome of several cases in which either sternal plating plus pectoralis major flap advancement or omental flap transposition or pectoralis major flap transposition has been used for repair of DSWIs.

\section{Patients and methods}

We performed a retrospective study of 36 patients over the period between January 2005 and December 2010, in the Maastricht University Medical Centre in the Netherlands.

\section{Outcome}

Next to gender, age and medical history of each patient, the clinical records were studied for data regarding indication for reconstructive intervention, detected pathogen in the sternum wound, type of surgical procedure, post-operative course and complications, additional treatment and followup. Therefore, we were able to retrospectively answer the following questions:

- What pathogen was detected in the sternal wound?

- Was VAC therapy applied before sternal wound reconstruction?

- Was the pectoralis plasty combined with sternal plating?

- Was the omentoplasty mono- or bipedicled?

- Was wound closure after omentoplasty obtained by primary closure or split-skin grafting plus VACtherapy?

- Did one of the following post-operative complications occur: infection of osteosynthesis material, fistula, sternum wound dehiscence, flap loss, herniation at donor site?
- How long did it take for the wound to be healed completely?

Measurements of the size of individual sternum wounds were not applicable from the clinical records.

Surgical technique

\section{Sternal plating and pectoralis major flap advancement}

After inspection of the wound for any signs of infection and a proper wound cleansing, bilateral mobilisation of the pectoralis major muscles is performed. The sternum is refixated with three up to five titanium plates and multiple screws. Then both pectoralis major flaps are approximated. Finally, two wound drains are placed and closure of the cutis is obtained with a stapler.

\section{Pectoralis major flap transposition}

First, the wound edges are excised, and if necessary, the sternum is fixated. A rotation flap of one breast is incised, initiated over the inframammary fold, then the pectoralis muscle is undermined in lateral direction, and at last, the flap is detached from the subcutis and transposed to the defect. The other breast is mobilised over the pectoralis muscle and rotation advancement is performed. After this procedure, two wound drains are applied and the cutis is primary closed.

\section{Pedicled omentoplasty}

After debridement of the sternal wound edges, a median laparotomy $( \pm 10 \mathrm{~cm})$ is performed. The omentum is detached from the transverse and mesocolon. Based on the surgeon's preference, a decision is made whether the right or left gastroepiploic artery (or both) should be spared. The right gastroepiploic artery is larger and has more epiploic branches and therefore is generally used as a nutrient vessel. After ligation of one gastroepiploic artery, the branches of the stomach from the gastroepiploic arcade are divided as far as necessary to obtain a real pedicled omentoplasty. Compression or kinking of the vascular pedicle is prevented. An artificial incisional hernia with sufficient diameter is left in the midline laparotomy wound for passing the pedicled omentoplasty through cranially. Via the subcutaneous route, the thoracic region is reached. The omentum is then placed without any traction in the sternum defect and fixed with some sutures at the edges. The sternum wound is either primary closed or covered by a 1 or 1.5 -meshed split-skin graft. All patients received antibiotic and thrombotic prophylaxis during the procedure. 


\section{Results}

All 36 patients, 28 men and 8 women in this study suffered from a DSWI after CABG; their average age was 68.3 years. Before sternal wound repair VAC-therapy was applied in all patients, duration ranging from 2 up to 5 weeks (see Table 1). Staphylococcus aureus was the most detected pathogen in the sternal wounds ( $47.2 \%$, see Table 2$)$; these patients were treated with flucloxacillin. Patients with a positive Staphylococcus epidermis (27.8\%) or Escherichia coli $(2.8 \%)$ were given amoxicillin and clavulanate. For the Klebsiella pneumonea, ciprofloxacin was prescribed.

In 22 patients, the cardiothoracic surgeon obtained sternal refixation by sternal plating combined with bilateral pectoral major flap advancement. Fourteen patients, suffering from post-sternotomy wound infection after CABG, needed plastic reconstructive surgery, either omentoplasty $(n=11)$ or pectoralis major flap transposition $(n=3)$.

Table 1 Patients and methods

Preoperative characteristics

\begin{tabular}{|c|c|}
\hline Deep sternal wound infection & 36 \\
\hline Male-female ratio & $28: 8$ \\
\hline Age (years): average and range & $68.3[47-82]$ \\
\hline Weight $(\mathrm{kg})$ : average and range & $83.6[66-113]$ \\
\hline $\begin{array}{l}\text { Body mass index }\left(\mathrm{kg} / \mathrm{m}^{2}\right) \text { : } \\
\text { average and range }\end{array}$ & $29.5[23.1-38.0]$ \\
\hline Hypertension & $28(77.8 \%)$ \\
\hline Hyperlipidaemia & $19(52.8 \%)$ \\
\hline Diabetes mellitus & $10(27.8 \%)$ \\
\hline $\begin{array}{l}\text { Chronic obstructive pulmonary } \\
\text { disease }\end{array}$ & $6(16.7 \%)$ \\
\hline $\begin{array}{l}\text { Haematocrit (\%): average and } \\
\text { range }\end{array}$ & $33[25-50]$ \\
\hline $\begin{array}{l}\text { Preoperative vacuum-assisted } \\
\text { closure therapy (VAC) }\end{array}$ & 36 \\
\hline \multicolumn{2}{|l|}{ Intervention } \\
\hline $\begin{array}{l}\text { Pectoralis major flap } \\
\text { transposition }\end{array}$ & 3 \\
\hline $\begin{array}{l}\text { Sternal plating + pectoralis major } \\
\text { flap transposition }\end{array}$ & 22 \\
\hline $\begin{array}{l}\text { Pedicled omentoplasty }+ \text { primary } \\
\text { closure }\end{array}$ & $7^{\mathrm{a}}$ \\
\hline $\begin{array}{l}\text { Pedicled omentoplasty }+ \text { split skin } \\
\text { graft }+ \text { VAC }\end{array}$ & 4 \\
\hline \multicolumn{2}{|l|}{$\begin{array}{l}\text { Vascular pedicles for omentum } \\
\text { transposition }\end{array}$} \\
\hline 2 gastroepiploic arteries & 5 \\
\hline 1 gastroepiploic artery & 6 \\
\hline
\end{tabular}

${ }^{\mathrm{a}}$ Two patients underwent omentoplasty combined with pectoralis plasty in the same stage, due to extensive soft tissue loss
Table 2 Pathogens detected in sternum wound

\begin{tabular}{llc}
\hline Pathogen & $n$ & Percentage (\%) \\
\hline Staphylococcus aureus & 17 & 47.2 \\
Escherichia coli & 1 & 2.8 \\
Staphylococcus epidermis & 10 & 27.8 \\
Klebsiella pneumonea & 1 & 2.8 \\
No pathogen detected & 7 & 19.4 \\
\hline
\end{tabular}

Transposition of the greater omentum was performed either for primary reconstruction, in cases with extended sternum defects and extensive soft tissue loss or when initial wound closure with sternal plating and pectoralis plasty $(n=4)$ had failed.

Sternal plating and pectoralis major flap advancement

In 22 patients with DSWI, sternal refixation was performed by the cardiothoracic surgeon, by applying sternal plates and additional bilateral pectoralis major flap advancement to achieve closure of the sternal defect. Fifteen patients recovered without any complications after this refixation procedure (see Table 3). In seven patients, the sternal plates were removed a few months after placement, due to infected material $(n=4)$ or a fistula $(n=3)$. Because of sternal pain complaints, three other patients had their sternal plates removed after the sternum wound had already completely healed. Overall, sternal wound healing was achieved in an average 7.7 weeks for this group (see Table 4).

\section{Pectoralis major flap transposition}

Three patients, who suffered from a DSWI after CABG, received only a regional myoplasty for reconstruction. In two cases, a unilateral pectoralis major muscle was transposed to the defect; in one case, pectoralis transposition was combined with advancement of the contralateral breast. Average wound healing time was 8 weeks (see Table 4) and the postoperative course was uneventful for all three patients (see Table 3).

Pedicled omentoplasty

Eleven patients underwent omental flap transposition. In four patients, a pedicled omentoplasty and split-skin graft was performed for reconstruction of the sternal defect. These patients were also treated with additional VAC therapy on top of the split-skin graft. Seven other patients received pedicled omentoplasty with primary closure of the sternal wound; in two cases omentoplasty was combined 
Table 3 Postoperative complications

\begin{tabular}{|c|c|c|c|c|c|c|}
\hline Type of intervention & $\begin{array}{l}\text { Wound } \\
\text { dehiscence }\end{array}$ & $\begin{array}{l}\text { Flap } \\
\text { loss }\end{array}$ & $\begin{array}{l}\text { Incisional } \\
\text { hernia }\end{array}$ & $\begin{array}{l}\text { Infected sternal } \\
\text { plate }\end{array}$ & Fistula & Uncomplicated \\
\hline Omentoplasty & $3(27.3 \%)$ & - & $2(18.2 \%)$ & - & - & $6(54.5 \%)$ \\
\hline Omentoplasty+primary closure & 3 & - & - & - & - & 4 \\
\hline Omentoplasty + split skin graft + VAC & - & - & $2^{\mathrm{a}}$ & - & - & 2 \\
\hline Pectoralis plasty & $2(8 \%)$ & - & - & $4(16 \%)$ & $3(12 \%)$ & $18(72 \%)$ \\
\hline $\begin{array}{l}\text { Sternal plating }+ \text { bilateral pectoralis major } \\
\text { flap advancement }\end{array}$ & 2 & - & - & 4 & 3 & 15 \\
\hline $\begin{array}{l}\text { Bilateral pectoralis major flap (rotation) } \\
\text { advancement }\end{array}$ & - & - & - & - & - & 3 \\
\hline
\end{tabular}

${ }^{a}$ One hernia was corrected with a mesh, one hernia was treated expectative

with pectoralis major flap transposition due to extensive soft tissue loss. The omentum was bipedicled in five patients; in six patients, it was pedicled on one gastroepiploic artery (see Table 1).

Flap loss did not occur in any of these patients. Six patients had an uneventful post-operative course. Wound dehiscence occurred in three patients, in which the cutis had been primary closed after omentoplasty. Moreover, one of these patients died shortly after the procedure because of recurrent bleeding from his right cardiac ventricle. Two patients needed a necrosis necrotectomy of the wound, one patient also needed additional VAC therapy.

In two other cases, a herniation of the donor site occurred. In one patient, a wait-and-see policy was followed, while in another patient, a mesh was applied for hernia repair, 4 months after the omentoplasty (see Table 2). Three months after this initial hernia repair, the patient needed a re-operation for recurrence of the herniation. A few months later, the wound still showed $1.5 \mathrm{~cm}$ of wound dehiscence. Eventually, 14 months after the omentoplasty, a stage IIIB non-small cell lung carcinoma was detected in this patient, which could possibly also have affected the complicated post-operative course for this patient. Average wound healing time after omentoplasty accounted 11.6 weeks (see Table 4).

Table 4 Sternal wound healing

\begin{tabular}{lc}
\hline Intervention & $\begin{array}{c}\text { Sternal wound } \\
\text { healing (weeks) }\end{array}$ \\
\hline $\begin{array}{l}\text { Sternal plating + bilateral pectoralis } \\
\text { major flap advancement }\end{array}$ & 7.7 \\
Uni-/bilateral pectoralis major flap & 8.0 \\
advancement & 11.6 \\
Omentoplasty & 9.3 \\
Omentoplasty+ primary closure & 15.0 \\
Omentoplasty+split skin graft+VAC & \\
\hline
\end{tabular}

\section{Discussion}

According to Daya [7], sternal internal plate fixation for definitive wound closure after VAC therapy is an effective method for repair of post-sternotomy wound infection or dehiscence. In line with this, Baillot et al. [9] conclude in a large 15-year review that VAC therapy with sternal preservation, followed by delayed sternal plating and pectoralis major flap advancement forms a good therapeutic strategy. Notably, in that study, most patients treated with VAC therapy showed decreased perioperative mortality and increased short-term survival, compared to patients treated without VAC. In our series, all patients were initially treated with VAC therapy (and antibiotics) before repair of the sternum was obtained.

Our study shows an overall positive post-operative course in twenty-four cases $(66.7 \%)$. Because findings in literature lack a large multi-centre controlled trial comparing myoplasty to omentoplasty, controversy still remains in this area of plastic reconstructive surgery.

Ortak et al. summarise that pectoralis major flap should be first choice in treatment of DSWI [10]. Another retrospective analysis concludes that in case of DSWI, after sternal debridement and VAC therapy, pectoralis major flap transposition is a safe technique and should be considered as primary reconstruction choice [11]. Myoplasty with pectoralis major flap is not feasible in a patient with previous axillary radiation therapy, or in a patient with low muscle density, or in patients with extensive soft tissue loss in the sternal area, especially in the lower mediastinum.

Given its rich vascularisation and angiogenic and immunogenic features, the greater omentum seems an ideal and outmost viable solution for the repair of infected sternotomy wounds [12]. Lopez-Monjardin et al. [13] conclude in their study that mediastinal reconstruction using the omentum flap in patients with mediastinitis secondary to open heart surgery is associated with fewer septic complications than using the 
pectoralis major flap. Also, reconstruction of a chest wall defect after full-thickness resection for local recurrence or primary malignancy of the chest wall can be successful with pedicled omentoplasty and split-skin graft with absorbable implants [14].

Nowadays, pedicled omentoplasty is reserved for situations in which myocutaneous flap coverage has failed or where myoplasty is not sufficient. Use of musculocutaneous flaps also depends on the vitality and the condition of the regional muscles. By not making use of the omentum, the patient can be spared a laparotomy. Besides, the greater omentum is not always available, for example, when a patient already had previous abdominal surgery.

Ghazi et al. [15] report an overall recipient-site morbidity of $23 \%$ and a donor-site complication rate of $27 \%$ in a group of 52 patients, in which the greater omentum was used for the reconstruction of infected sternotomy wounds. These percentages of flap-related complications and donorsite complications match with our results.

A disadvantage of the transposition of the omentum is that the abdominal cavity has to be opened, with complications appearing in up to $18.5 \%$ of cases, usually not life-threatening. Reported complications involve gastrointestinal and abdominal wall complications, such as ileus, hernia or abdominal wall infection [16]. In our study, incisional herniation occurred in 2 of 11 patients (18.2\%) treated with omentoplasty.

Laparoscopically harvested omentoplasty, compared to the open procedure, is a minimally invasive technique with several advantages, for example, a decrease in the chance of herniation of the donor site [17].

Van Geel et al. reported that reconstruction with omentoplasty after extended thoracic wall resection, is a significant prognostic factor for complications (OR, 2.24; 95\% CI 1.094.62; $P$ value 0.004 ), based on a multivariate analysis of a retrospective study $(n=220)$. In almost all patients in this study, the chest wall defect was repaired with a pedicled omentoplasty and split-skin graft. In 17 patients, secondary wound dehiscence occurred; in 12 patients, over $50 \%$ of the omentoplasty became necrotic [18].

Wound dehiscence occurred in 3 out of 11 patients from our omentoplasty series. As described above, in one omentoplasty case, a more complicated post-operative course regarding herniation and slow wound healing occurred. Moreover, it is worth noting that not before 15 months after the omentoplasty, this patient appeared to be affected with non-small cell lung carcinoma. Two patients treated with a pedicled omentoplasty also needed a pectoralis plasty during the same procedure because of extensive soft tissue loss.

Given the previously discussed advantages and disadvantages of both flaps, the choice for either omentoplasty or pectoralis plasty will probably remain dependent on experience of the individual surgeon, complexity of the wound, but moreover on availability, quality and vitality of the donor site. Based on our results, it does not seem to make a difference in clinical outcome, whether the omentum is pedicled on one or two gastroepiploic arteries.

Recommendations for clinical practice

Based on our experience, including both cardiothoracic and plastic surgeons, in case of DSWI, we would recommend initial preservation of the sternum with VAC therapy followed by delayed sternal refixation and bilateral pectoralis major flap advancement. This is in line with the review of Baillot et al. [9].

Most infected sternum wounds, even more complicated infections, have been solved after completion of VAC therapy and secondary sternal osteosynthesis plus pectoralis plasty. Although, in few cases, the sternal plate got infected or a fistula occurred, the sternum was not compromised in its functionality and stability.

Finally, pedicled omentoplasty should be reserved for cases in which the sternum has recurrently fallen open after previous sternal plate refixation, or for cases in which the sternum defect is too extended and/or soft tissue loss is too extensive.

Conflicts of interest There is no conflict of interest reported by the authors.

Open Access This article is distributed under the terms of the Creative Commons Attribution Noncommercial License which permits any noncommercial use, distribution, and reproduction in any medium, provided the original author(s) and source are credited.

\section{References}

1. Mauermann WJ, Sampathkumar P, Thompson RL (2008) Sternal wound infections. Best Pract Res Clin Anaesthesiol 22(3):423436

2. Cayci C, Russo M, Cheema FH, Martens T, Ozcan V, Argenziano $M$ et al (2008) Risk analysis of deep sternal wound infections and their impact on long-term survival: a propensity analysis. Ann Plast Surg 61(3):294-301

3. Schroeyers P, Wellens F, Degrieck I, De Geest R, Van Praet F, Vermeulen $Y$ et al (2001) Aggressive primary treatment for poststernotomy acute mediastinitis: our experience with omental- and muscle flaps surgery. Eur J Cardiothorac Surg 20(4):743-746

4. Shumacker HB Jr, Mandelbaum I (1963) Continuous antibiotic irrigation in the treatment of infection. Arch Surg 86:384-387

5. Malmsjo M, Ingemansson R, Sjogren J (2007) Mechanisms governing the effects of vacuum-assisted closure in cardiac surgery. Plast Reconstr Surg 120(5):1266-1275

6. Sjogren J, Malmsjo M, Gustafsson R, Ingemansson R (2006) Poststernotomy mediastinitis: a review of conventional surgical treatments, vacuum-assisted closure therapy and presentation of the Lund University Hospital mediastinitis algorithm. Eur J Cardiothorac Surg 30(6):898-905 
7. Daya M, Barnes N (2009) Use of VAC therapy and sternal plating in the treatment of sternotomy wound dehiscence. Eur J Plast Surg 32:287-291

8. Chang RR (2006) Chapter 68: Thoracic reconstruction. In: Grabb WC, Smith JW, Thorne CH, Bartlett SP, Beasley RW, Aston SJ et al (eds) Grabb and Smith's Plastic Surgery, 6th edn. Lippincott Williams \& Wilkins, Philadelphia, USA, pp 665-669

9. Baillot R, Cloutier D, Montalin L, Cote L, Lellouche F, Houde C et al (2010) Impact of deep sternal wound infection management with vacuum-assisted closure therapy followed by sternal osteosynthesis: a 15-year review of 23,499 sternotomies. Eur J Cardiothorac Surg 37(4):880-887

10. Ortak T, Uraloğlu M, Uysal A, Orbay H, Tekin F, Șensöz O et al (2007) Reconstruction of sternal defects with pectoralis major muscle flap. Eur J Plast Surg 30(5):223-228

11. Ennker IC, Pietrowski D, Vohringer L, Kojcici B, Albert A, Vogt PM et al (2009) Surgical debridement, vacuum therapy and pectoralis plasty in poststernotomy mediastinitis. J Plast Reconstr Aesthet Surg 62(11):1479-1483

12. Krabatsch T, Fleck E, Hetzer R (1995) Treating poststernotomy mediastinitis by transposition of the greater omentum: late angiographic findings. J Card Surg 10(1):46-51
13. Lopez-Monjardin H, de-la-Pena-Salcedo A, Mendoza-Munoz M, Lopez-Yanez-de-la-Pena A, Palacio-Lopez E, Lopez-Garcia A (1998) Omentum flap versus pectoralis major flap in the treatment of mediastinitis. Plast Reconstr Surg 101(6):1481-1485

14. Contant CM, van Geel AN, van der Holt B, Wiggers T (1996) The pedicled omentoplasty and split skin graft (POSSG) for reconstruction of large chest wall defects. A validity study of 34 patients. Eur J Surg Oncol 22(5):532-537

15. Ghazi BH, Carlson GW, Losken A (2008) Use of the greater omentum for reconstruction of infected sternotomy wounds: a prognostic indicator. Ann Plast Surg 60(2):169-173

16. Hultman CS, Carlson GW, Losken A, Jones G, Culbertson J, Mackay $\mathrm{G}$ et al (2002) Utility of the omentum in the reconstruction of complex extraperitoneal wounds and defects: donor-site complications in 135 patients from 1975 to 2000. Ann Surg 235(6):782-795

17. Puma F, Fedeli C, Ottavi P, Porcaro G, Battista Fonsi G, Pardini A et al (2003) Laparoscopic omental flap for the treatment of major sternal wound infection after cardiac surgery. J Thorac Cardiovasc Surg 126(6):1998-2002

18. Van Geel AN, Lans TE, Wouters MWJM, Van der Pol CC, Schmitz PIM (2009) Indicaties en complicaties van uitgebreide thoraxwandresecties. Ned Tijdschr Oncol 6(6):262-271 